PALABRAS CLAVE

Política social

Equidad

Administración pública

Programas de acción

Mitigación de la pobreza

América Latina

Ana Sojo

Oficial de Asuntos Sociales,

División de Desarrollo Social,

CEPAL

- ana.sojo@cepal.org
REVISTA DE LA CEPAL 91・ABRIL 2007

\section{La trayectoria del vínculo entre políticas selectivas contra la pobreza y políticas sectoriales}

\author{
Ana Sojo
}

$\mathrm{E}$

análisis conceptual e histórico de experiencias paradigmáticas de política social en la región muestra hitos fundamentales en la trayectoria del vínculo entre las políticas selectivas contra la pobreza y las políticas sociales sectoriales. Esos hitos surgen de cambios en las políticas de focalización y de algunas reformas a las políticas de carácter universal de los sectores sociales. Aquí se destacan los planteamientos de redistribución con crecimiento; las posteriores propuestas reduccionistas de focalización, que sufrieron desplazamientos conceptuales y efectivos a lo largo de las dos últimas décadas, y la preocupación por interactuar con lo sectorial de algunos programas contemporáneos de transferencias condicionadas que, por su escala, sobresalen en la región. También se consideran dos tendencias relacionadas, que operan en campos que trascienden lo que es estrictamente la lucha contra la pobreza: la propuesta reduccionista del manejo del riesgo social y, en sentido contrario, las garantías de prestaciones en salud. 
I

\section{Introducción}

Este análisis abordará el vínculo de las políticas selectivas con las políticas sociales sectoriales y sus implicaciones de carácter institucional, entrelazando los ángulos conceptual e histórico. Se muestra cómo este vínculo ha estado condicionado por las orientaciones diversas que han tenido las políticas de focalización. También por las perspectivas conceptuales pertinentes que han estado en boga, de modo que sus avatares han estado sometidos en cierta medida a la caducidad intrínseca de las modas intelectuales o políticas que a la larga ponen en evidencia limitaciones no avizoradas y llevan finalmente a reformular las políticas y sus objetivos. A su vez, algunas reformas de las políticas universales ${ }^{1}$ de los sectores sociales también han condicionado la trayectoria de las políticas de focalización.

Se consideran aquí cuatro hitos en la trayectoria de las políticas selectivas que han tenido repercusiones en esa relación. Con tal fin, se analiza en primer lugar la focalización y su vínculo con los planteamientos de redistribución con crecimiento. En segundo lugar, se examinan las posteriores propuestas reduccionistas de focalización, considerando sus desplazamientos conceptuales y efectivos a lo largo de las dos últimas décadas. En tercer lugar, se escudriña cómo ha ido ganando terreno la preocupación por interactuar con lo sectorial en algunos programas contemporáneos de transferencias condicionadas que, por su escala, sobresalen en la región. Finalmente, se tratan políticas selectivas que, aunque en algunos casos pudieran ser subsumidas en políticas contra la pobreza, generalmente, por la índole de propias prestaciones y objetivos, las trascienden. El examen de los diferentes temas se hace profundizando en aspectos de los programas y experiencias que han resultado paradigmáticos en la región, que se concentran en Bolivia, Brasil, Chile y México. Otras experiencias de la región se reseñan brevemente.

\section{II}

\section{Algunas precisiones preliminares}

Dado el énfasis del análisis, no serán consideradas las políticas asistenciales tradicionales, pasadas o contemporáneas, ya que al tener como objetivo primordial cultivar clientelas para lograr su apoyo político con una perspectiva de corto plazo, a menudo carecen de nexos sólidos con los sectores sociales de vocación universalista u operan relativamente aisladas de ellos. Estos débiles eslabonamientos hacen que, por lo general, la

\footnotetext{
$\square$ Una versión preliminar de este artículo fue publicada en Sojo (2007). La autora agradece la eficiente asistencia de Lourdes Colinas en la recolección parcial de información sobre los programas de transferencias condicionadas.

${ }^{1}$ Las políticas universales se sustentan en el principio de universalidad, que establece los niveles de protección que la sociedad puede garantizar a todas las personas en tanto ciudadanos, con independencia de su condición socioeconómica o de su capacidad de pago. En este último sentido es inseparable del principio de solidaridad, según el cual el sistema de derechos y prestaciones es financiado por los miembros de la sociedad con aportes diferenciados proporcionales a su capacidad económica.
}

ejecución de esas políticas tampoco esté asociada al desmantelamiento de programas universales con los cuales pudieran competir.

En la historia de la política social, los programas asistenciales tradicionales han tenido hasta hoy mayor presencia cuanto más endebles sean las instituciones formales de la política social y más arraigado el clientelismo como regla del juego de la mediación política. ${ }^{2}$ Han cubierto una amplia gama de prestaciones, como transferencias de ingreso, programas de alimentación

\footnotetext{
${ }^{2}$ El clientelismo tampoco parece estar siempre confinado a programas contemporáneos con sistemas de selección de beneficiarios y criterios explícitos vinculados con lo sectorial. Una evaluación del programa brasileño de becas escolares Bolsa Escola constató que en los ámbitos municipales más politizados de Brasil parece existir menor preocupación porque las condiciones asociadas con los beneficios efectivamente se satisfagan, por ejemplo, respecto de la educación. Diversos análisis de regresión sugieren que algunas variables de carácter político podrían influir en los procesos de registro de beneficiarios (de Janvry, Finan y otros, 2005, pp. 21 y 25).
} 
y subsidios en salud, vivienda y otros. Dado su alto grado de discrecionalidad y su orientación clientelista, se caracterizan generalmente por utilizar instrumentos de selección de beneficiarios muy frágiles, debido a la ausencia de criterios selectivos con fundamento técnico orientados a atacar la pobreza en sus raíces. Representativa en este sentido, y desarrollada al calor de las políticas populistas tan en boga en el siglo XX en la región, fue la denominada "Obra social" de Evita Perón, que ofrecía importantes prestaciones en vivienda y salud y dio gran popularidad a su inspiradora en la población argentina.

En sentido estricto, preferimos el término selectividad al de focalización. Como señalamos hace tiempo, este último no expresa adecuadamente la idea de selectividad y hasta resulta tautológico, pues toda política -incluidas las políticas sociales universales de las cuales pretenden desligarse las de focalización (targeting) — apunta a una población-objetivo.
Conviene además tener presente que focalización es un vocablo indeterminado y carente de rigor (Sojo, 2000), ya que se usa para denominar una amplia gama de políticas y programas, en la cual destacan programas concebidos como redes de protección para la extrema pobreza; programas para aliviar perturbaciones en los ingresos, como los implantados en Argentina al inicio del presente siglo; programas asistenciales de corte tradicional; programas de transferencias monetarias condicionadas en un marco de derechos y obligaciones (por ejemplo, el Programa Puente en Chile o el Programa Oportunidades en México), y programas vinculados o no con lo sectorial. Recientemente ha surgido además el concepto de "cuerdas de protección", para programas afines al aseguramiento destinados a proteger a sectores sociales vulnerables que no son exclusivamente pobres (Pritchett, 2005, pp. 17-19). Pero, dado que el término focalización se ha utilizado profusamente, es inevitable usarlo en este análisis para entablar el diálogo, procurando hacer explícito su significado a lo largo del texto.

\section{III}

\section{Focalización en el marco de la redistribución con crecimiento}

En la década de 1970, el concepto de focalización estuvo asociado con los planteamientos sobre redistribución con crecimiento, lo cual le imprimió determinadas características: el eje del análisis se hallaba en las causas estructurales de la pobreza; la focalización no se centraba en la política social y, en materia de política social, no se planteaba que ella se redujera a programas estrictamente para los pobres. Tales intervenciones eran únicamente parte de un espectro de políticas de redistribución del ingreso, que debían modificar la concentración de capital físico y humano para permitir a los pobres el acceso a destrezas, capital físico, activos complementarios, servicios públicos e inversión pública. La focalización en política social debía garantizar el acceso a los servicios, eliminar filtraciones hacia los grupos no definidos como beneficiarios y tener en cuenta que servicios como los materno-infantiles y de nutrición eran complementos necesarios de una estrategia orientada hacia la inversión (Sojo, 1990). ${ }^{3}$

\footnotetext{
${ }^{3}$ Véase en Chenery y otros (1976) los planteamientos de Ahluwalia y Chenery; de Chenery y Duloy, y de Rao.
}

Se consideraba una amplia gama de instrumentos redistributivos: mercado de factores; propiedad y control de activos; impuestos sobre los ingresos personales y sobre la riqueza; provisión de bienes de consumo público; mercados de mercancías; intervención en el desarrollo tecnológico. Dadas las múltiples dimensiones de los objetivos redistributivos de la política económica, se creía necesario usar diversos instrumentos (Ahluwalia, en Chenery y otros, 1976, p. 125). La focalización, al centrarse en las causas de la pobreza y no en sus síntomas, abarcaba también los activos en tanto determinantes del ingreso, y apuntaba a identificar diferentes grupos de pobres que debían tener acceso a activos específicos. Por su parte, los servicios materno-infantiles y de nutrición eran "...un complemento necesario de una estrategia orientada hacia la inversión..." (Ahluwalia y Chenery, en Chenery y otros, 1976, p. 77). Los pobres debían recibir los subsidios de los servicios públicos para, con tal beneficio, elevar también su productividad (Rao, en Chenery y otros, 1976).

Los grupos-objetivo debían corresponder a “...un grupo de personas que, además de ser pobre, es 
relativamente homogéneo con respecto al efecto que un conjunto dado de instrumentos de política puede tener sobre él" (Bell y Duloy, en Chenery y otros, 1976, p. 127) y se debían eliminar las filtraciones de beneficios de algunos programas hacia quienes no fueran definidos como tales (Chenery y Duloy, en Chenery y otros, 1976). Sin embargo, se reconocían las dificultades inherentes a prestar más servicios a los pobres sin reducirlos en otros sectores, y la resistencia que estos últimos sectores opondrían a perder sus privilegios (Rao, en Chenery y otros, 1976).

En términos institucionales, la gama de áreas de intervención era amplia e implicaba de hecho la acción y coordinación de las diversas entidades pertinentes. Sin embargo, el enfoque en materia de política social, que estaba puesto en lo sectorial, no contemplaba modificar la dinámica sectorial tradicional, según la cual cada sector social actuaba primordialmente de manera autónoma, y sin mayor coordinación con los otros. Como se verá enseguida, los planteamientos de redistribución con crecimiento, tan bien orientados a hacer hincapié en las causas de la pobreza y la consideración de sus variadas dimensiones, se mostrarían notablemente debilitados a inicios de los años 1980.

\title{
IV
}

\section{La focalización reduccionista y sus desplazamientos conceptuales y fácticos}

\author{
“..[las intenciones reduccionistas] no son gratuitas. Siempre forman \\ parte de una iniciativa mayor, de algún proyecto para reformar por \\ completo el panorama intelectual y también nuestra actitud ante la \\ vida... la reducción nunca tiene un valor neutral, nunca está dirigida \\ solo a la simplicidad. Usted puede preguntar: \\ ¿la reducción se propone siempre de algún modo desacreditar o \\ degradar lo que se reduce?"
}

Mary Midgley ${ }^{4}$

Con el paso del tiempo, los postulados sobre focalización sufrieron cambios profundos, que se condensaron en los años 1980, cuando el planteamiento de la focalización se vio sometido a una reducción de carácter conceptual y político, elaborada al socaire de sendas propuestas de reforma de las políticas sociales formuladas por algunos gobiernos o por organismos como el Banco Mundial. Cabe conceptuar esta propuesta como reduccionista, ${ }^{5}$ ya que sistemáticamente identificaba elementos negativos de los programas de alcance universal para apoyar el reemplazo del principio de universalidad por el de focalización. Este último era esgrimido como principio

\footnotetext{
${ }^{4}$ Cita tomada del trabajo "Reductive megalomania" (Midgley, 1995) y traducida del inglés por la autora del presente artículo.

5 Aunque el término "reduccionismo" aún no se acepta en español, lo hemos adoptado como traducción del concepto anglosajón reductionism, debido a su indudable valor epistemológico.
}

articulador general y postrero, que a la vez delineaba un orden más simple y acotado para la política social: el de ser subsidiaria en materia de pobreza. También operaba el reduccionismo en tanto que a partir de atributos imputados a la focalización en materia de eficacia, eficiencia y equidad, se limitaban tanto los objetivos como los ámbitos de acción de la política social a aquellos que, en sentido estricto, más bien podrían serlo de un cierto tipo de focalización.

De allí que el reduccionismo haya articulado una perspectiva global sobre política social que, por su simpleza, era atractiva en aquel tiempo ortodoxo del ajuste estructural. Sin embargo, como la experiencia ciertamente se encargará de mostrar, su viabilidad y puesta en práctica serían muy complejas, debido a su carácter polémico y excluyente. En el marco de propuestas privatizadoras de las políticas sociales que constreñían la solidaridad de su financiamiento, se 
abogó por desmantelar los servicios sociales de alcance universal —evaluados muy negativamente mediante un giro analítico que extrapoló la regresividad de programas como los de pensiones a la generalidad de los programas universales - y por concentrar el gasto público social en los grupos más vulnerables mediante los llamados programas focalizados.

Se postuló que, a diferencia de la provisión universal, caracterizada como muy costosa e ineficiente, la focalización podía permitir que los gobiernos redujeran la pobreza con más eficacia y menor costo. Por ejemplo, Franco propuso la focalización como instrumento, postulado y principio orientador fundamental de la política social, en reemplazo de las "políticas generales" y "tradicionales", que tendían a ser de alto costo y bajo impacto en los sectores más afectados y habían fracasado en su intento de llegar a los pobres; estimaba que la focalización, por el contrario, permitía hacer un uso más racional de los recursos públicos, alcanzar más eficazmente los objetivos de los programas sociales, utilizar los recursos disponibles con mayor eficiencia e incrementar el efecto sobre la población-objetivo; asimismo, aseveraba que había tenido impactos positivos en el índice de desarrollo humano logrado por Chile a fines de los años 1980. Por tales motivos, opinaba que los recursos del gasto social así orientados debían también incrementarse (Franco, 1990, pp. 184-189; 1996, p. 18).

En cuanto a la morfología sectorial, se promovió fortalecer la atención primaria en salud y la educación primaria en detrimento de los otros niveles. Y, last but not least, el énfasis en propuestas asistenciales que debían amortiguar el impacto de los programas de ajuste desvió el interés hacia los síntomas de la pobreza, relegando a un segundo plano el tema de sus causas, que había estado presente en los planteamientos pertinentes de los años 1970. Pese a las singularidades de la trayectoria de los países y a la especificidad de sus problemas, y generalmente sin que ello estuviera sustentado en investigaciones o conocimientos precisos (van de Walle, 1995), se supuso que la focalización era un instrumento eficiente, eficaz y de validez general. La propuesta global sobre política social se articuló en torno a los siguientes planteamientos (Sojo, 1990):

i) contribuir a solucionar la crisis fiscal del Estado con modificaciones del gasto social;

ii) concentrar el gasto público social en los grupos más vulnerables de la población y restringir la acción del Estado en materia de política social. Se cuestiona y evalúa negativamente el principio de universalidad de la política social, extrapolando, por ejemplo, la profusa regresividad de los sistemas de pensiones al gasto social en general. Se propone el desmantelamiento relativo y variable de las políticas universalistas;

iii) preconizar la privatización relativa de los servicios sociales, incluso para los programas focalizados. En este ámbito no se presta mayor atención a los problemas que origina la prestación privada de servicios — la selección de riesgos, por ejemplo- debido a las fallas de los mercados;

iv) confiar en que la distribución primaria del ingreso y la elevación del nivel de vida, producto del derrame y de la reactivación económica, garantizarán a los grupos ajenos a la focalización la capacidad de pago para utilizar los servicios privados.

En la visión conservadora en América Latina, las políticas de focalización implantadas en Chile durante la dictadura militar se constituyeron en paradigmas de la política social. Hay que tener presente que tal concepción y experiencia se daban en uno de los países de la región donde el Estado de bienestar había logrado un desarrollo significativo hasta inicios de los años 1970 y que, por lo tanto, había requerido sendas reformas de los sectores sociales para las cuales la focalización cumplió un papel ancilar. Avanzar en una radical redefinición de las reglas del juego para proveer y financiar los servicios sociales fue viable gracias al contexto autoritario, que originó la desarticulación política de sus potenciales opositores, tanto de los partidos como entre los proveedores públicos y los tradicionales beneficiarios de las políticas sociales.

Como contrapunto, la focalización fue también relevante en otro país de la región que sobresalía en los años 1980 por sus altos índices de pobreza, rezagos en inversión social, endebles prestaciones de política social y grandes carencias de infraestructura social, problemas agudizados todos por la crisis económica. Es el caso de Bolivia, donde la focalización se vigorizó en el marco de políticas de estabilización y ajuste macroeconómico que lograron abatir la hiperinflación. En lo que concierne al presente análisis, cabe destacar del caso boliviano el papel del Fondo Social de Emergencia (FSE) —más tarde transformado en el Fondo de Inversión Social (FIS) - como vehículo primigenio de la focalización. El éxito en materia de estabilización macroeconómica arropó también al Fondo, erigido por el Banco Mundial como instrumento ejemplar para la región en materia de focalización.

En otras latitudes de América Latina, el reduccionismo no ganó tanto terreno. Por ejemplo en Brasil donde, por el contrario, hubo un ímpetu universalista en materia de política social, con fuerte asidero en la 
Constitución acordada en la transición a la democracia y con grandes repercusiones en materia de política social; basta recordar la implantación del Sistema Único de Salud (sus) en la reforma de la salud. Además, es interesante considerar que en ese país la falsa dicotomía entre focalización y universalismo polarizó en los años 1980 el debate acerca de programas para combatir la pobreza, por lo cual incluso no se implantó un acceso selectivo a los programas de asistencia social. Hacia mediados de los años 1990 se legitimaron políticas focalizadas de lucha contra la pobreza, pero no opuestas a los programas sociales de carácter universal. Se afirma que ese "retraso" en la instauración de políticas focalizadas permitió beneficiarse de la experiencia latinoamericana, aprendizaje que coartó la creación de programas redundantes o ajenos a los servicios básicos de vocación universal, o la instauración de fondos sociales de emergencia (Draibe, 2006, p. 143).

También avanzó el universalismo en Colombia, donde la compleja reforma de la salud buscó tanto la cobertura universal del aseguramiento y de la prestación de servicios como la competencia entre aseguradores y prestadores en el marco de un sistema solidario y descentralizado, cuyos beneficios y obligaciones están consolidados en dos regímenes: el contributivo, que se nutre de contribuciones obrero-patronales, y el subsidiado. El sistema colombiano cuenta con importantes dispositivos para la solidaridad, como el Fondo de Solidaridad y Garantía (FOSYGA).

En Costa Rica, país de arraigadas tradiciones universalistas, tampoco tuvo lugar un retroceso, entendido como un reduccionismo en la política social que se sesgara contra los recursos destinados a los sectores sociales. Incluso se consolidaron esfuerzos señeros en materia de políticas selectivas destinadas a estrechar la brecha digital, con la introducción de la informática educativa en el país, empezando por las escuelas más pobres pero en un horizonte universalista de expansión de la cobertura y cuyos objetivos claramente trascendían una orientación asistencial (Sojo, 1993).

Es relevante considerar las repercusiones que tuvo el giro hacia una focalización reduccionista en la dinámica de los sectores sociales. Especialmente ilustrativos son los casos de Chile y de Bolivia, por el importante impacto que tuvieron los planteamientos reduccionistas y porque además sus experiencias ejercieron cierta influencia en las políticas contra la pobreza y en la política social de la región.

En Chile, la focalización durante la dictadura militar fue funcional a las reformas de los sectores sociales, que apuntaban a desmantelar la solidaridad del financiamiento, acotar la prestación de servicios universales, lograr que la población no clasificada como pobre adquiriera servicios sociales de mercado, establecer subsidios a la demanda para que los pobres tuvieran acceso a prestaciones de mercado, y traspasar sendas funciones a los entes municipales en materia de salud primaria y de educación. Fueron ingentes los recursos que se destinaron a privatizar el sistema de pensiones y a consolidar las instituciones de salud previsional.

Como se aprecia, la focalización fue de la mano de profundos cambios en la dinámica de los sectores sociales, y graves fueron las consecuencias de esa constelación. En el sector salud, por ejemplo, la contracción del gasto, los recortes de los gastos de operación e inversión y la concentración de recursos en el nivel primario, sobre todo en el programa materno-infantil y en acciones de intervención nutricional ${ }^{6}$ dan cuenta de una relación perversa entre focalización y deterioro del sector salud. Como reconociera el propio Banco Mundial, a pesar de la avanzada transición epidemiológica del país, la expansión de la atención primaria se dio en detrimento del nivel terciario y la prioridad asignada a la atención materno-infantil menoscabó la atención de adultos y de la tercera edad y las respectivas acciones preventivas y curativas, causando desequilibrios en el sistema de salud y disminuyendo la eficiencia técnica y económica del uso de insumos (Sojo, 1996, p. 130).

Sin embargo, y a la luz de la positiva valoración que actualmente se realiza sobre los programas contemporáneos de transferencias condicionadas, cabe destacar un rasgo positivo de la focalización en aquel período en Chile, que sigue resultando interesante y que Pilar Vergara denominara entonces la medida más innovadora en materia de integración de los programas sociales contra la extrema pobreza: la vinculación de la transferencia monetaria denominada Subsidio Único Familiar (SUF) al programa materno-infantil y, por consiguiente, al Programa Nacional de Alimentación Complementaria (PNAC) que existía desde 1954, y a la asistencia escolar de los niños. Además de operar como mecanismo de autoselección, el requisito tenía la virtud de promover el acceso de los pobres a aquel programa de alimentación. Los beneficiarios del SUF también tenían acceso gratuito a todas las atenciones médicas del Servicio Nacional de Salud, derecho que la reforma de la salud introducida en el período había negado a los mayores de seis años (Vergara, 1990, p. 325).

\footnotetext{
${ }^{6}$ Fundamentalmente las del Programa Nacional de Alimentación Complementaria (Vergara, 1990, pp. 250-251).
} 
Otro rasgo típico de la focalización reduccionista en Chile fue la limitada escala de los programas, que excluía a un número muy importante de personas que hubiesen necesitado tales prestaciones, y que también redundó en prestaciones de poco valor monetario y baja calidad. Sin ir más lejos, el propio SUF, concebido de manera integral, disminuyó a la mitad el valor real de las transferencias entre su creación en 1981 y el año 1987. En el caso del PNAC, las restricciones de recursos llevaron a abandonar la orientación preventiva en materia de nutrición, a restringir el número de prestaciones y a reducir la población beneficiaria, primero solo a niños desnutridos, luego a aquellos en riesgo de desnutrición o en pobreza crítica y, a partir de 1985, a niños con síntomas evidentes de desnutrición (Vergara, 1990, pp. 71 y 96).

Por su parte, del caso boliviano cabe considerar el papel que cumplió el Fondo Social de Emergencia — convertido más tarde en Fondo de Inversión Social- por el carácter paradigmático que se pretendió atribuirle en la región. Cuando se implantaron los fondos sociales de emergencia, su operación autónoma respecto de los ministerios y de los sectores sociales fue destacada como una de sus virtudes y postulada como garantía de agilidad, eficacia y eficiencia. En el marco de las políticas de ajuste se consideraron poco los aspectos sociales; se pretendía que el derrame brindara oportunidades para los pobres y que, en el corto plazo, los fondos sociales de emergencia compensaran algo las pérdidas de ingreso de los sectores más afectados. Los fondos se destinaron a crear empleo, a infraestructura en áreas pobres, a brindar transferencias monetarias y a otros propósitos. Los programas eran asistenciales, y su visibilidad y efectos de demostración cumplían un importante papel estrictamente político: en Bolivia se seleccionaron las zonas de mayor riesgo político para invertir los recursos. Así, se logró visibilidad política, a pesar de que la pequeña escala de dichos recursos y de la cobertura no posibilitaba efectos anticíclicos.

Los fondos de emergencia e inversión social establecieron como prioridad la creación de empleo. Sin embargo, los empleos generados fueron generalmente de pequeña escala, de muy baja calidad y con bajas remuneraciones, y además con sesgos desfavorables a las mujeres. Siendo el empleo uno de los principales mecanismos para combatir la pobreza usado por los fondos, se evidenciaba así la escasa consideración de las especificidades de la pobreza en el perfil de sus programas (Berar Awad, 1997).

Sus relaciones competitivas con lo sectorial, más que garantizar agilidad o eficiencia, incrementaron la fragmentación administrativa de las políticas universales, pues se añadieron superposiciones y duplicidades, o bien se provocaron discontinuidades con la dinámica sectorial. En Bolivia, por ejemplo, hubo situaciones dramáticas cuando se construyeron escuelas o instalaciones de salud sin haber contado con los recursos humanos y la infraestructura física adicional requeridos para su funcionamiento.

Por lo tanto, la institucionalidad asociada con los fondos de emergencia y de inversión social planteaba problemas: los vínculos con los ministerios y con los sectores sociales eran muy débiles. Generalmente estos fondos estaban a cargo de entidades autónomas y transitorias que, por ejemplo, contaban con más financiamiento externo o cuyos funcionarios tenían sueldos mucho mayores que los del resto de las instituciones públicas. Como consecuencia, su continuidad y replicabilidad eran muy acotadas, puesto que la institucionalidad pública no contaba con tales recursos. A lo largo del tiempo, ello derivó en críticas que, por ejemplo, señalaban la importancia de vincular a los ministerios la dinámica de los fondos y programas contra la pobreza, considerando que los sectores sociales tienen la mayor infraestructura y proveen la mayoría de los servicios sociales (MesaLago, 1993; Cornia, 1999).

Resultan también muy interesantes las evaluaciones críticas y matizadas sobre el desempeño de los fondos sociales, realizadas en el seno de instituciones que los financiaron o apoyaron. De los variados aspectos allí considerados, rescatamos solo algunos que atañen directamente al vínculo entre políticas selectivas y la dinámica de los sectores sociales (Banco Mundial, 2002, pp. 34-38). Por ejemplo, se constató que los fondos eran percibidos como entes competitivos y con privilegios respecto de la dinámica sectorial, lo cual originaba fricciones y contribuía a establecer la idea de que sus aciertos son atribuibles a su disponibilidad de recursos. Si bien se han establecido mecanismos para velar por que los ministerios comprometan recursos para gastos recurrentes vinculados a las instalaciones provistas por los fondos sociales-compromisos que a veces no son cumplidos por restricciones presupuestarias-, las inversiones de esos fondos a menudo no se insertan en sólidas políticas sectoriales o en estrategias de inversión pública, y la aprobación de sus subproyectos por parte de los ministerios puede adquirir un carácter rutinario.

Cuando los fondos han representado una parte sustancial del gasto social, como ha ocurrido en Bolivia, Honduras y Nicaragua, se ha informado incluso de algunos impactos institucionales desfavorables para la planificación sectorial. También se ha cuestionado la 
eficiencia de su asignación de recursos, y los críticos plantean que se han socavado los esfuerzos por mejorar la transparencia, la rendición de cuentas y los procesos integrales de elaboración del presupuesto.

En relación con el horizonte temporal de acción de los fondos, otros análisis han sostenido que estos instrumentos pueden diluir o posponer reformas sectoriales, menguar la capacidad de los ministerios correspondientes para asignar recursos con criterios sectoriales, y promover sesgos de los donantes hacia la inversión más que hacia los gastos corrientes, lo cual puede afectar la calidad y los resultados de los servicios ofrecidos. Se aprecia en las evaluaciones allí sistematizadas de qué manera una visión negativa de las políticas universales y la creencia de que los problemas de pobreza se iban a resolver fundamentalmente con programas focalizados, se tradujeron en una determinada relación entre programas selectivos y sectoriales que, al coartar reformas indispensables de las políticas universales, puede tener un efecto negativo a mediano o largo plazo.

Afortunadamente, el carácter polémico y radical de la perspectiva reduccionista en materia de focalización condujo a debates — como se vio incluso en el seno del Banco Mundial, principalmente a nivel técnico_- sobre sus orientaciones y alcances. Posiblemente haya contribuido en el mismo sentido cierta inflexión del pensamiento de este organismo, que se reflejó en su Informe sobre el desarrollo mundial de 1997: el Estado en un mundo cambiante, ${ }^{7}$ respecto al vínculo entre crecimiento y equidad y a la concepción de Estado y mercado.

\footnotetext{
${ }^{7}$ Banco Mundial (1997). La estrategia de desarrollo allí propuesta niega las contraposiciones (trade-offs) entre crecimiento y equidad, y afirma una relación complementaria entre Estado y mercado. La perspectiva temporal dista del corto plazo asociado con las propuestas de ajuste. En cuanto a los servicios básicos, el informe plantea una posición flexible respecto de su provisión, financiamiento y regulación, según las fortalezas relativas de las agencias estatales, del mercado y de la sociedad civil; hay cautela ante los mecanismos de mercado: no está probado que el uso de vales o bonos (vouchers) mejore el desempeño; la contratación de servicios, por su parte, debe hacerse especificando muy bien los productos, y se dificulta cuando la falta de competencia no facilita la comparación del desempeño. A diferencia de los años 1980, la pobreza se sitúa en un marco más amplio y entre las funciones del Estado se contempla la redistribución de activos para incrementar la equidad. La reducción de la pobreza se relaciona con cinco ingredientes cruciales: fundamento en la ley; ambiente benigno para las políticas, lo que incluye estabilidad macroeconómica; inversión en personas e infraestructura; protección de los vulnerables y protección del medio ambiente. Sin embargo, una rígida distinción entre bienes públicos y privados, o bien cierto desprecio de las externalidades de los bienes privados, tiene sendas implicaciones a la hora de definir ámbitos de acción de la política social y de establecer los niveles de prestación de servicios en los sectores de educación y salud: por ejemplo, las intervenciones curativas en el campo de la salud se definen como un bien casi exclusivamente privado que, si el Estado no las financia,
}

Gradualmente, la perspectiva global sobre política social propia de la oblicuidad reduccionista fue erosionada por consideraciones de muy diverso tipo, de las cuales cabe sintetizar y destacar las siguientes (Sojo, 1999):

i) economía política: no solo los pobres deben beneficiarse de la política social, ya que los cambios estructurales necesitan el apoyo de coaliciones políticas más amplias, que pueden verse apuntaladas por una política social de mayor alcance;

ii) viabilidad: la viabilidad de establecer programas focalizados aislados es limitada ya que, de hecho, la mayoría de los programas selectivos de la región se llevan a cabo en el marco de servicios sociales básicos con los que se relacionan;

iii) rescate de las especificidades nacionales de la pobreza: hay planteamientos que reconocen que el énfasis en políticas macro, sectoriales y focalizadas debe ser función de la profundidad y naturaleza específica de la pobreza en cada país. La focalización es incluso más importante cuando la pobreza es muy concentrada y la capacidad de ejecución buena; pero, según se plantea, cuando la pobreza está muy difundida y la capacidad de ejecución es débil, los frutos del crecimiento y el apoyo de los servicios sociales básicos son las vías más efectivas para enfrentarla;

iv) apreciaciones matizadas sobre la universalidad: por ejemplo, respecto del sector salud, se estima que las políticas universales son progresivas cuando la cobertura universal es efectiva y se han eliminado las desigualdades inherentes a los sistemas de financiamiento con niveles múltiples. Pero se plantea que tales políticas tienen como condición que el grueso de la fuerza laboral tenga un empleo formal, y que existan recursos financieros, capacidad administrativa y determinación política;

v) exigencias de gestión de la focalización: para ser eficaz la focalización necesita cierta institucionalidad, así como recursos técnicos y financieros, lo que debilita el planteamiento de que ella garantiza la reducción de la pobreza a menor costo;

vi) a partir de experiencias exitosas de desarrollo en el sudeste asiático, los organismos financieros internacionales adoptaron un enfoque del capital humano algo más flexible, que considera relevante

todos, excepto los pobres, encontrarán alguna manera de financiarlas (Sojo, 1999). Sobre las implicaciones de este último postulado en otros contextos, véase más adelante críticas a postulados semejantes en el manejo del riesgo social, y también las reflexiones contenidas en la sección VI. 
también la educación secundaria y, con ello, la interacción de los diferentes niveles de prestación de servicios;

vi) la experiencia asiática también revitalizó planteamientos de los organismos financieros internacionales sobre la necesidad de mejorar la distribución del ingreso en aras de un mayor crecimiento e integración social: se afirma que en aquellas latitudes las menores desigualdades de ingreso han tenido un efecto positivo en el crecimiento, tanto en forma indirecta como directa. Esto abre espacio, nuevamente, para dar mayor importancia a las causas de la pobreza;

vii) ganaron terreno, incluso en el seno del Banco Mundial, concepciones sobre desarrollo que niegan las contraposiciones entre crecimiento y equidad, que reconocen una relación complementaria entre Estado y mercado, y que muestran cautela ante los mecanismos de mercado por consideraciones de eficiencia y equidad.

Estos cuestionamientos, que surgieron a mediados de los años 1990 y se han ido acentuando hasta hoy, modificaron en diversa medida las orientaciones globales en materia de política social y de focalización, según las circunstancias nacionales y la idiosincrasia específica de los programas. ${ }^{8}$ En cuanto a postulados, cabe destacar que la CEPAL plasmó a inicios del milenio cinco principios rectores de la política social de la región, a saber: universalidad, solidaridad, eficiencia, equivalencia e integralidad. En ese marco, la selectividad o focalización se concibió como el conjunto de instrumentos que permite asignar recursos subsidiados a los más pobres y cumple una función complementaria, ya que “... no es una política social, sino una condición que, bien aplicada, hace más eficaz la universalización de los programas sociales" (CEPAL, 2000, p. 81, y en general pp. 80-87).

Los cuestionamientos no significan que las tesis reduccionistas en materia de política social hayan sido

\footnotetext{
${ }^{8}$ Por ejemplo, una relación complementaria entre políticas universales y selectivas se fundamentó y planteó explícitamente en el Plan nacional de lucha contra la pobreza. Hacia una Costa Rica integrada por las oportunidades (Gobierno de Costa Rica, Segunda Vicepresidencia, 1996). Hasta entonces las propuestas reduccionistas de focalización no habían ganado mucho terreno en ese país. Pero se ha afirmado que ese documento marcó un punto de inflexión, al postular la articulación de las políticas sociales universales y selectivas, poner en el centro del debate el tema de la coordinación y presentar un decálogo de principios orientadores de la lucha contra la pobreza. Asimismo, que demarcó los planes de gobiernos ulteriores, de modo que su enfoque ha estado presente en los diez últimos años (Barahona, 2006, pp. 68 y 69). La CEPAL brindó cooperación técnica en la concepción de dicho plan.
}

superadas en general como propuesta para América Latina y el Caribe. Más aún, a fines de los años 1990 emergió un reduccionismo remozado, esta vez en relación con el aseguramiento. En el marco de la reflexión sobre el riesgo económico y social de la región y sobre los mercados de aseguramiento, adquiere relevancia para América Latina y el Caribe la propuesta de manejo del riesgo social (social risk management), ${ }^{9}$ que articula una visión sobre políticas de aseguramiento con propuestas globales sobre política social (Holzmann y Jorgensen, 2000; Banco Mundial, 2001).

Aunque la influencia de esta última propuesta en el diseño de políticas públicas pueda verse limitada por el relativo hermetismo de su terminología, sus postulados tienen evidentes pretensiones paradigmáticas, no solo respecto de políticas de aseguramiento, sino también del combate contra la pobreza y la delimitación de las políticas sociales, que entronizan una responsabilidad social mínima para enfrentar la inseguridad económica. En este caso, a diferencia de la focalización reduccionista nacida al socaire del ajuste estructural, se atribuye mayor importancia a las causas de la pobreza, y se recurre a una terminología propia del ámbito del aseguramiento (Sojo, 2003, pp. 133).

El análisis del manejo del riesgo social apunta certeramente a que todas las personas son vulnerables a múltiples riesgos de diverso origen, e interrelaciona el riesgo, la exposición al riesgo y la vulnerabilidad. Constituyen riesgos los eventos que pueden dañar el bienestar y que son inciertos en cuanto a su ocurrencia, su duración o la magnitud del daño que pueden causar. Se entiende por exposición la probabilidad de que un riesgo ocurra. La vulnerabilidad mide la capacidad de resistencia a una perturbación o choque y, por lo tanto, la probabilidad de que esta se traduzca en una declinación del bienestar, la que dependerá sobre todo de la dotación de activos de los hogares, de los mecanismos de aseguramiento y de la severidad y frecuencia de la perturbación. La protección social, acto seguido, es definida como el conjunto de intervenciones públicas que ayudan a los individuos, hogares y comunidades en el manejo del riesgo y que apoyan a los más pobres; tales intervenciones deben establecer relaciones de refuerzo mutuo con las áreas de educación y salud en torno al desarrollo de capital humano.

Pero, partiendo del tema del riesgo y del aseguramiento, se formula una propuesta global de política

\footnotetext{
${ }^{9}$ La síntesis y crítica de la propuesta de manejo del riesgo social aquí considerada se han tomado casi literalmente de Sojo, 2003.
} 
social que plantea una combinación público-privada cuyas delimitaciones y naturaleza le son funcionales, y que gira en torno a tres planteamientos básicos: las responsabilidades del Estado en materia de bienestar social se circunscriben al combate contra la pobreza; se establece el aseguramiento contra los riesgos como una responsabilidad individual, y se desestima en lo fundamental la solidaridad en la diversificación de riesgos. En esos términos, el aseguramiento individual en el mercado, la provisión de servicios para los pobres mediante redes de protección y la focalización contrapuesta a la universalidad, conforman una estrategia de política social que dispone una responsabilidad pública mínima en materia de protección social, deposita el financiamiento y la prestación de los demás servicios relacionados con el bienestar social en manos privadas y reitera la desestimación del principio de solidaridad del financiamiento. De allí la analogía que puede establecerse con las propuestas reduccionistas de política social asociadas con la focalización (Sojo, 2003, p. 134).

Esta propuesta soslaya el hecho de que la acción del Estado o la participación obligatoria en una mancomunación (pool) de riesgos es pertinente no solo cuando los mecanismos de mercado no existen, colapsan o son disfuncionales, puesto que las asimetrías de información y las fallas de mercado no son fenómenos excepcionales, sino inherentes a los mercados de aseguramiento. En esos términos, la regulación pública, el aseguramiento público, o el aseguramiento social con aseguradores privados pero con mecanismos de financiamiento obligatorio y regulaciones que garanticen la diversificación del riesgo, permiten enfrentar la selección del riesgo e incrementar la eficiencia de estos mercados, al propiciar la estabilidad del aseguramiento. Cuando se opta por el financiamiento solidario, los objetivos, además, son redistributivos y es posible establecer subsidios cruzados entre diversos estratos de ingreso, grupos de edad, de riesgo u otros. Las asimetrías de información y fallas de mercado del aseguramiento están relacionadas con múltiples elementos, entre los que sobresalen: la selección adversa; las conductas de riesgo moral; las complejidades y opacidades que la naturaleza y la calidad del producto - es decir, el aseguramiento y las prestaciones en sus diversas variantes - ofrecen al consumidor; la complejidad y heterogeneidad del producto asociado al aseguramiento (como en el caso de las prestaciones de salud); las externalidades del consumo, y la existencia de subconsumo por la incapacidad de pagar las primas de un seguro privado debido a bajos ingresos o a enfermedades crónicas o congénitas, en cuyo caso no se tiene acceso al aseguramiento aunque el mercado exista (Sojo, 2003, p. 131).

El alto nivel de subconsumo en aseguramiento que se observa en la región no afecta solo a los pobres. El sistema de precios del aseguramiento de mercado restringe su cobertura y su monto para vastos sectores de la población, y el limitado aseguramiento social solidario impide estrechar la brecha entre los niveles efectivos de ingresos y los niveles deseados de aseguramiento. $\mathrm{Al}$ estar en jaque la capacidad de diversificar riesgos, el impacto sobre el bienestar es grave y se coartan los efectos redistributivos del financiamiento solidario entre grupos de ingreso, de edad y de riesgo.

\section{Los programas contemporáneos de}

\section{transferencias monetarias condicionadas}

\section{y su vínculo con los sectores sociales}

Tras los cuestionamientos sintetizados en la sección anterior, se inauguró una fase en materia de focalización en la cual ha ganado terreno la vinculación de programas selectivos con lo sectorial y con sus programas, eminentemente de carácter universal, al establecerse condiciones para acceder a ciertos beneficios, por lo general monetarios. Las prestaciones universales —inmersas por naturaleza en la dinámica sectorial — constituyen una bisagra entre obligaciones y derechos, que actúa en un amplio espectro temporal e invierte en capital humano. Los efectos que se buscan pueden ir desde la restauración de la salud hasta la disminución de la desnutrición potencial o efectiva o la mejora del acervo educativo de las personas, de modo que pueden darse en el mediano y largo plazo, y ser incluso intergeneracionales. Las acciones en 
educación actúan contra una inserción prematura y por ende desmedrada en el mercado laboral.

A pesar de que en el mismo período se acuñó el llamado Consenso de Washington, la heterodoxia en las políticas contra la pobreza fue ganando terreno en los años 1990, debido al desgaste de los planteamientos reduccionistas en materia de política social y de focalización. Se acotó el sentido de la selectividad, al reconocerse cada vez más que la complejidad de objetivos de la política social trasciende la lucha contra la pobreza, que la propia lucha contra la pobreza es una tarea ingente que sobrepasa ampliamente a la focalización, que el carácter multifacético de la pobreza impone políticas integrales y heterogéneas e intervenciones diferenciadas, y que se debe incidir en las causas de la pobreza, haciendo hincapié en la adquisición de capacidades, destrezas y habilidades que permitan superarla, mediante la inserción social, económica y política (Sojo, 1999).

La naturaleza asistencial o de inversión en capital humano de los programas o de aportes como las transferencias monetarias, se relaciona con la estrategia en que se insertan las prestaciones. De allí que sea pertinente analizar las funciones simultáneas que ellos pueden cumplir, tales como actuar contra los efectos temporales de ajustes económicos, acercar o integrar la poblaciónobjetivo a la oferta de educación y salud; o también conocer sus efectos indirectos, como por ejemplo, las modificaciones de la microfísica del poder en los hogares, cuando las mujeres son las depositarias de las transferencias monetarias o de otro tipo de beneficios condicionados y deben velar por el cumplimiento de las obligaciones contraídas. Hay que tener presente tales consideraciones cuando se analizan las tendencias en materia de focalización. La naturaleza heterodoxa que esta ha adoptado gradualmente, al menos en los países que, en términos relativos, le destinan más recursos, parece haberse nutrido de lecciones dejadas por fracasos y limitaciones acaecidos al calor del reduccionismo, y tal vez refleje también el efecto de algunas críticas oportunas de autoridades en la materia (Atkinson, 1995; Sen, 1995).

En estos términos, los programas de transferencias condicionadas de ingreso plantean contraprestaciones relacionadas principalmente con la inversión en capital humano, mediante acciones de educación, nutrición y salud de niños y jóvenes. Se trata de combatir la deserción escolar, el rezago escolar y la inserción prematura y precaria en el mercado de trabajo. Para que esta tarea sea eficaz, se involucra a otros miembros de la familia, sobre todo a las mujeres. Cuando la contraprestación significa alguna forma de inserción laboral, ello recae en los jefes de hogar y, en ese caso, se trata de programas de empleo. Los programas de empleo se han desarrollado tanto en Bolivia, país con una extendida pobreza crónica, como en Argentina, país con una amplia pobreza reciente asociada con desempleo y caída de los ingresos causados por perturbaciones macroeconómicas. Está en juego entonces la existencia de una oferta sectorial que haga viable las contraprestaciones. Es decir, que no solo no existe una contraposición con la lógica sectorial, sino que la lógica es complementaria. Por otra parte, el carácter condicionado de las prestaciones implica considerar a la familia como un todo (Serrano, 2005; CEPAL, 2006). ${ }^{10}$

Entre las implicaciones institucionales de la heterodoxia pueden destacarse las siguientes:

i) la necesaria coordinación de las políticas contra la pobreza con la política macroeconómica y las políticas de desarrollo productivo ${ }^{11}$ y su vinculación con las reformas generales de política social. La experiencia de Chile y la de Brasil son muy interesantes al respecto. En el caso chileno hay vinculaciones, incluso presupuestarias, entre unas y otras políticas. El programa Puente, por ejemplo, transfiere recursos a los ministerios para que atiendan a determinadas poblaciones que el programa selecciona. Es decir, es el programa Puente el que cuenta con montos dados de recursos que deberán ser invertidos, por ejemplo, por el Ministerio de Educación, mediante un convenio, en la educación de determinados beneficiarios;

ii) la inserción estratégica de la selectividad como complemento de las instituciones vigentes y no en competencia con ellas. Es el caso del programa de desarrollo humano Oportunidades en México o del de becas escolares (Bolsa Escola) en Brasil, que después se incorporó en un programa más amplio (Bolsa Familia): todos ellos corresponden a transferencias efectuadas con una perspectiva integral. El hecho de establecer derechos y obligaciones de los beneficiarios tiene consecuencias: es preciso tomar medidas para que los beneficiarios puedan hacer efectivos sus derechos y obligaciones. En otras palabras, tiene que garantizarse el acceso efectivo a una oferta pública, generalmente de carácter sectorial en salud y educación, cuando se exige una contraprestación por parte de los beneficiarios.

\footnotetext{
${ }^{10}$ Véase en el apéndice un cuadro sinóptico de los programas.

${ }^{11}$ Sobre los efectos de las políticas macroeconómicas y el desempeño económico en el bienestar en Costa Rica, El Salvador y Honduras, véase Sánchez (2005).
} 
Tal inserción estratégica y complementaria tiene repercusiones globales en la política social y su ámbito institucional;

iii) la necesidad de velar por que los recursos destinados a estos programas sean sustentables. ${ }^{12}$

Cabe reiterar que, en un sentido estricto, las prestaciones condicionadas no son radicalmente nuevas..$^{13} \mathrm{El}$ punto de inflexión de algunos programas de transferencias monetarias condicionadas contemporáneas que han tenido cierto efecto de demostración en la región - como el Oportunidades y el Bolsa Familia - es la escala de sus beneficiarios. Hasta el año 2006, el programa Bolsa Familia tenía como objetivo cubrir a 11,2 millones de familias (Cohn y Medeiros, 2004). El cuadro 1 muestra los importantes recursos y la creciente cobertura del programa Oportunidades de México, mientras que el cuadro 2 evidencia los modestos recursos con que sigue contando el Programa de Asignación Familiar (PRAF) en Honduras.

El Plan Jefes y Jefas de Hogar, introducido en Argentina en enero de 2002, fue también de gran escala y tuvo como objetivo paliar la vulnerabilidad de familias afectadas por la pobreza y el desempleo tras las perturbaciones macroeconómicas del 2001. Este plan, uno de los más grandes de su género en la región, cubría a finales del 2000 cerca de dos millo-

\footnotetext{
${ }^{12}$ En este marco resulta particularmente interesante la Ley general de desarrollo social de México, promulgada en 2004, que aglutina varios elementos de esta visión heterodoxa. Uno de sus principios es la solidaridad, entendida como la colaboración entre personas, grupos sociales y órdenes de gobierno, con responsabilidad compartida, para mejorar la calidad de vida de la sociedad. El principio de integralidad, por su parte, se refiere a la articulación y complementariedad de programas y acciones que vinculen los diferentes beneficios sociales en el marco de la política nacional de desarrollo social. De acuerdo con los artículos 14 y 18 de la Ley, la política de desarrollo social incluye como sus vertientes: acciones sectoriales y relativas al empleo, seguridad social y programas asistenciales, desarrollo regional, infraestructura social básica y fomento del sector social de la economía. El destino del gasto en desarrollo social está protegido; el gasto social per cápita no puede ser menor en términos reales que el del año inmediatamente anterior (con lo cual el año 2004 se convierte en el año base) y su distribución se sustenta en criterios de eficacia, cantidad y calidad. Véase SEDESOL (2004, primera sección, pp. 3-14).

${ }^{13}$ Ya se analizó la temprana experiencia del Programa Nacional de Alimentación Complementaria (PNAC) en Chile. Otro programa de prestaciones condicionadas introducido tempranamente fue el Programa de Asignación Familiar (PRAF) en Honduras, que nació como una suma de programas, con una institucionalidad débil y con recursos limitados. Sus prestaciones, entre ellas bonos alimentarios, bolsones escolares, programas de apoyo a la microempresa, de desarrollo integral de la mujer y de atención materno-infantil, se diseñaron para apoyar la inserción en el sistema educativo y el acceso a la salud. Más tarde, el PRAF se amplió, cubriendo tiendas de consumo, bancos comunales exclusivamente femeninos, proyectos productivos del subprograma de desarrollo integral de la mujer y bonos a la tercera edad (CEPAL, 1998). Al respecto véase el cuadro 2.
}

nes de hogares. Para asegurarse de que la población beneficiaria era efectivamente la más necesitada, como contraprestación se exigía trabajar. Hay evaluaciones que muestran que los criterios de selección (los beneficiarios debían ser jefes/jefas de hogar desempleados) no siempre se cumplieron, ya que algunos participantes, sobre todo mujeres, no estaban insertos en el mercado laboral antes de producirse las perturbaciones macroeconómicas; se ha calculado que la mitad de los beneficiarios estaban previamente inactivos, que el plan había contribuido a reducir la extrema pobreza en $2 \%$ y que, sin el plan, un $10 \%$ de sus beneficiarios podría haber caído en la pobreza extrema (Galasso y Ravallion, 2003).

CUADRO 1 México: indicadores de escala del programa
Oportunidades, 2000 y 2006

\begin{tabular}{|c|c|c|}
\hline Nivel/ año & 2000 & 2006 \\
\hline Familias & 2470000 & 5000000 \\
\hline Personas & 12350000 & 25000000 \\
\hline Becarios educación primaria & 1677138 & 2867760 \\
\hline Becarios educación secundaria & 808185 & 1734643 \\
\hline Becarios educación media y superior & - & 696353 \\
\hline Adultos mayores & - & 820000 \\
\hline Localidades rurales & 52373 & 87720 \\
\hline Localidades semiurbanas & 851 & 2493 \\
\hline Localidades urbanas & 8 & 500 \\
\hline Municipios & 2166 & 2435 \\
\hline
\end{tabular}

Fuente: Gómez-Hermosillo (2006).

CUADRO 2

Honduras: población atendida por el Programa de Asignación Familiar (PRAF) (En porcentaje)

\begin{tabular}{lccc}
\hline $\begin{array}{l}\text { Categoría de } \\
\text { beneficiarios }\end{array}$ & $\begin{array}{c}\text { Población proyectada } \\
\text { por el Instituto Nacio- } \\
\text { nal de Estadística (INE) }\end{array}$ & $\begin{array}{c}\mathrm{N}^{\mathrm{o}} \text { de } \\
\text { beneficiarios }\end{array}$ & $\begin{array}{c}\text { Población } \\
\text { atendida } \\
(\%)\end{array}$ \\
\hline $\begin{array}{l}\text { Mujeres en edad } \\
\text { fértil y niños } \\
\text { menores de } 6 \text { años }\end{array}$ & 2625399 & 241308 & 9,2 \\
$\begin{array}{l}\text { Niños en edad } \\
\text { escolar } \\
(7 \text { a 12 años) }\end{array}$ & 1158820 & 160872 & 13,9 \\
$\begin{array}{l}\text { Población de 3 } \\
\text { a 64 años }\end{array}$ & 4521886 & 51196 & 1,1 \\
$\begin{array}{l}\text { Adultos mayores } \\
\text { (65 años y más) }\end{array}$ & 292766 & 46666 & 15,9 \\
\hline
\end{tabular}

Fuente: Presidencia de la República de Honduras, Programa de Asignación Familiar (PRAF). 
CUADRO 3

América Latina (cuatro países): escala de algunos programas de transferencias condicionadas, diferentes años

\begin{tabular}{lllc}
\hline País & $\begin{array}{l}\text { Programa y año } \\
\text { de la estimación }\end{array}$ & Beneficiarios & $\begin{array}{c}\text { Gasto en el programa } \\
\text { como porcentaje del PIB }\end{array}$ \\
\hline Brasil & Bolsa Familia, 2006 & $65 \%$ de las familias pobres & $0,41^{\mathrm{a}}$ \\
Chile & Chile Solidario, 2004 & $6,45 \%$ de la población & 0,10 \\
Colombia & Familias en Acción, 2001 & $4 \%$ de la población & 0,3 \\
Honduras & Programa de Asignación Familiar (PRAF) & (Véase el cuadro 2) & $0,3^{\mathrm{b}}$ \\
\hline
\end{tabular}

Fuente: CEPAL (2006) y los propios programas.

a Proyecciones de Afonso, recogidas por Draibe (2006).

b Proyecciones según cifras preliminares del Banco Central proporcionadas por el PRAF en febrero del 2007.

Si se lograra que el financiamiento y la cobertura de planes y programas como los indicados estuviesen en adecuada relación con la magnitud de la pobreza, ellos podrían tener además algún efecto anticíclico. Sin embargo, el salto de escala de algunos programas no debe conducir a sobreestimar la participación global de las transferencias monetarias condicionadas en los recursos destinados a la política social, ni su participación en el PIB (cuadro 3). Generalmente, incluso en México o Brasil, las transferencias que reciben los beneficiarios son bajas; en el caso del programa Oportunidades se debate desde el 2006 la conveniencia de elevar el monto de las transferencias.

Por otra parte, cabe resaltar que la realización de las transferencias monetarias en forma eficiente, oportuna y acorde con los criterios de selección de beneficiarios implica grandes desafíos en materia de gestión. En ese sentido, son elocuentes los procesos de entrega regular y estabilizada de transferencias del programa Oportunidades, que se nutre de recursos dispersos y cuyo ciclo permanente, de carácter bimestral, se ajusta a la actualización del padrón y a la certificación permanente de corresponsabilidades. En el 2006, esa gestión implicaba realizar cálculos de apoyos monetarios para 10,3 millones de personas y dar seguimiento a su entrega con indicadores de control en tiempo real (Gómez-Hermosillo, 2006). En el actual debate sobre el futuro del programa, se ha afirmado que realizar transferencias monetarias - lo cual implica una selección actualizada de beneficiarios-es precisamente el meollo de sus competencias, para evitar una expansión hacia funciones prestadoras o incluso hacia corresponsabilidades nuevas o adicionales, por ejemplo, en el ámbito del aseguramiento (López Calva, 2006; Gertler, 2006).

En el caso de Brasil, el programa Bolsa Escola comenzó a innovar en materia de gestión, al eliminar intermediaciones burocráticas y transferir recursos direc- tamente a los beneficiarios, mediante tarjetas magnéticas de un banco público de amplia presencia nacional. Con el tiempo y en el contexto del programa Bolsa Familia, el banco se ha convertido en el organismo operador del padrón de beneficiarios, que ha llegado a constituirse en un registro único. En México, actualmente se discute sobre un registro único de beneficiarios de programas sociales y un sistema de selección de beneficiarios, a partir del padrón del programa Oportunidades y de los procedimientos en que este se genera.

Cada vez más se reconoce que los programas deben atender a las causas específicas de la pobreza y considerar su heterogeneidad, lo que exige intervenciones integrales y diferenciadas. ${ }^{14}$ Las transferencias condicionadas tienen como contraparte virtual la institucionalidad sectorial y, por lo tanto, no deben estar divorciadas de ella y menos aún en competencia; lo que se pretende es que contribuyan a la universalización y a salir de la pobreza (Cohn y Medeiros, 2004). Pero la interrelación de los programas selectivos con la institucionalidad sectorial es un proceso en marcha, que indudablemente estará sujeto a muchos ajustes.

En el caso de la red de protección social Chile Solidario, el programa Puente, que busca integrar socialmente a los más pobres acercándolos a la red de prestación de servicios públicos, establece un contrato con las familias beneficiarias que vincula la provisión de servicios por el Estado con tareas que ellas deberán cumplir, según las establezca el monitor. Esto significa que los sectores de salud, educación, trabajo y vivienda, entre otros, se comprometen específicamente a dar atención

\footnotetext{
${ }^{14}$ En la región se había insistido sobre la heterogeneidad de la pobreza y sus consecuencias para la focalización en términos de atender diversas carencias, y sus implicaciones para el diseño de los programas y de los criterios e instrumentos de selección de beneficiarios (Raczynski, 1991; Vergara, 1990; CEPAL, 1994).
} 
prioritaria a los beneficiarios y, cuando sea necesario, a reforzar sus redes prestadoras. Los promotores locales del programa identifican las redes existentes a las que pueden remitir las familias, y las intervenciones del programa son coordinadas a escala municipal. La puesta en marcha de Chile Solidario ha implicado cambios en las agencias gubernamentales involucradas y en sus interrelaciones. Involucra al Ministerio de Planificación y Cooperación, que está a cargo del programa; al Fondo de Solidaridad e Inversión Social (FOSIS), que ejecuta el programa Puente en los niveles central, regional y municipal, y a las entidades municipales, que en el caso de Puente crean una unidad de acción familiar mediante un convenio con el FOSIS. Ha habido fricciones entre el Ministerio de Planificación y el FOSIS, habiendo este último asumido el liderazgo debido a su pericia en la lucha contra la pobreza. Para poner en marcha una red multisectorial dedicada a la prestación de servicios hubo que establecer acuerdos a nivel nacional y regional para efectuar prestaciones. También han surgido tensiones con las municipalidades en torno a las áreas de influencia, los recursos y el uso político de estos. La promulgación de la ley de Chile Solidario permitió formalizar las normas de procedimiento (Palma y Urzúa, 2005).

La experiencia brasileña tiene una singularidad: los programas de carácter asistencial tradicionales no han sido el núcleo de la lucha contra la pobreza. Sí lo han sido los nuevos programas de transferencias condicionadas, que no conformaron una red social, pues emergieron de los ministerios sociales que brindan servicios sociales condicionados a las transferencias. Para no desligar a tales programas de la política social básica y de carácter universal, estando más avanzada la experiencia y conformado un catastro único de beneficiarios, se preservó la vinculación entre el beneficio monetario y el área prestadora y la "especialización" sectoriales. Esta fragmentación, se afirma, generaba una relación muy cercana con los prestadores, especialmente con la escuela y el consultorio de salud, que permitía maximizar la mejora del desempeño escolar o nutricional más allá del mero recurso monetario percibido. Los ministerios respectivos verificaban el cumplimiento de las obligaciones. Posteriormente, la instauración del programa Bolsa Familia en 2003 apuntó a unificar la gestión de los programas bajo el Ministerio de desarrollo social, y atribuyó importantes funciones a los municipios, en tanto que los ministerios siguieron regulando las condiciones de las corresponsabilidades y verificando el cumplimiento por parte de los beneficiarios. Algunos analistas han advertido del riesgo de "prefecturización" -mayor poder relativo del prefecto municipal, con posibilidades de sesgos clientelistas- que ha acarreado cierto distanciamiento de las instituciones escolares y de salud respecto del programa Bolsa Familia; asimismo, han señalado que está pendiente una prestación integral y articulada de servicios que debiera ser competencia de los entes prestadores (Draibe, 2006, pp. 144, 148, 153 y 173-175).

Por su parte, en evaluaciones del programa Oportunidades se ha recomendado que este tenga mayores vínculos con la operación tradicional de los programas de salud. Desde la perspectiva de los beneficiarios, esas actividades aparecen como rutinarias y desvinculadas de los beneficios del programa. Las reglas que rigen la operación de Oportunidades hacen que en el plano local este se vuelva un programa más, que se suma a los del sector de salud o educación, perdiendo la integralidad a la que aspiran las prestaciones condicionadas (Meneses, Almodóvar y otros, 2005, pp. 358 y 359 ).

En el debate que se da en el programa Oportunidades desde el 2006 ocupa un papel central su vinculación con las políticas sectoriales. La polémica se ha enfocado en torno a diversos temas. Uno de ellos es el efecto de la calidad de los servicios en el acervo de capital humano que se desea promover; entre los logros se señala mejor salud y nutrición de los niños, mayor escolaridad, y ciertas mejoras de la salud del adulto mayor. Pero preocupa que no por ello los niños van a dejar de ser pobres en el futuro, que el diseño de los incentivos no promueve transiciones claras hacia la educación secundaria y que se desconoce la calidad del aprendizaje y, en cuanto a salud, que son altas las tasas de obesidad, diabetes e hipertensión. También se señala como problema que los niños preescolares no son una población-objetivo. Esto pone sobre el tapete la calidad de la atención en salud, la vigilancia de la oferta escolar en cuanto a calidad y extensión, el desarrollo cognitivo preescolar -aspectos que están en manos de los entes sectoriales que prestan los servicios-y los mecanismos mediante los cuales el programa Oportunidades pudiera estimular mejoras de calidad en la oferta sectorial (Gertler, 2006; Alvarez, 2006).

Con base en evidencias sobre la calidad de la educación a la que tienen acceso los beneficiarios y sobre los efectos del programa Oportunidades, se ha planteado que para incrementar su impacto es fundamental mejorar la calidad de la oferta sectorial y buscar también efectos colaterales en los comportamientos de las familias: por ejemplo, que las familias perciban que los beneficios futuros de la educación son más altos que los que reciben actualmente (Parker, 2006). 
Asimismo, se ha sopesado la posibilidad de que la evaluación del programa Oportunidades se extienda a la oferta educativa y de apelar a acciones globales que apunten a mejorar la oferta educativa para los más pobres (Mancera, 2006).

En varias experiencias, conciliar la oferta sectorial con las prestaciones condicionadas requiere ampliar el gasto social, especialmente en educación y salud. Así, se reconoce que ampliar la cobertura de Oportunidades en México requiere de servicios de educación y salud que permitan, por ejemplo, que el programa cubra no solo las zonas de mayor concentración de pobreza sino que incorpore también a familias pobres en zonas de baja marginación y de reducida concentración de hogares pobres (Orozco y Hubert, 2005, p. 6). Por su parte, un descarnado análisis y balance de la dinámica de los sectores de salud y educación y de su coordinación con Oportunidades concluye que debe buscarse una consonancia de objetivos, ya que por ahora los vínculos con el programa son desconocidos para los sectores, no se integran esos objetivos dentro de los propios, no hay indicadores de operación ni de rendición de cuentas de los sectores específicos para Oportunidades, ni mecanismos eficaces de colaboración (Hernández, 2006).

En este sentido, como bien se ha señalado al examinar experiencias tan diversas como las de Chile y México, las transferencias condicionadas de ingreso no son sustituto de la provisión de una oferta de servicios sociales de calidad. Si no hay preocupación por proveer servicios de salud y educación de calidad, se corre el riesgo de condicionar las transferencias monetarias a proveedores que son ineficaces para lograr mejoras de largo plazo en el bienestar y para combatir las causas de la pobreza y su carácter intergeneracional. Esto lleva a plantear la ampliación de la cobertura de estos servicios en las áreas pobres y a que se vele por una mejor calidad de las prestaciones (Rawlings, 2004, p. 4; Serrano y Raczynski, 2003 y 2005). ${ }^{15}$

\footnotetext{
${ }^{15}$ Sin embargo, tal perspectiva no es compartida por algunos analistas. Por ejemplo, algunos postulan que, para hacer más eficiente el uso de recursos, las contraprestaciones deben asociarse a desplazamientos a zonas donde exista la oferta educativa, estimando ineficiente hacer transferencias para lograr asistencia escolar en lugares donde, por el mero hecho de existir oferta educativa, la propensión a asistir a la escuela es alta, con independencia del apoyo monetario. Sobre las mismas bases se califican de eficientes los subsidios al transporte hacia zonas con oferta educativa (de Janvry y Sadoulet, 2005). Se advierte en este enfoque cierto desprecio de los esfuerzos que pueden desplegarse para ampliar la cobertura sectorial, en este caso en salud, esfuerzos que evidentemente obligan a destinar más recursos al gasto social en aras de la equidad y no de apreciaciones reduccionistas de eficiencia.
}

En Costa Rica, actualmente el diseño de las prestaciones condicionadas se está haciendo en función de la dinámica sectorial, para que constituyan puentes que abran a los pobres el acceso a los servicios universales. Así, los programas de transferencias condicionadas deberán ayudar a combatir la baja cobertura y alta deserción en la educación secundaria, que afecta principalmente a los jóvenes pobres. ${ }^{16}$ Los compromisos de las familias, por lo tanto, no estarán centrados en el acceso a los servicios de salud, cuya cobertura en el país es muy alta (Zumbado, 2006, pp. 13 y 14).

Para que el entronque entre lo sectorial y lo selectivo sea viable es preciso modificar muchas veces la forma en que se han venido brindando las prestaciones. Por ejemplo, dar un salto en la calidad de la prestación de servicios no solo va en contra de sumar recursos para hacer lo mismo, sino que implica modificar la forma en que se organizan los servicios, las reglas del juego y los incentivos, y también la evaluación del uso de los recursos. Tales cambios no disfrutan de la misma popularidad que las ampliaciones de cobertura, basadas fundamentalmente en el incremento de los recursos, pues como se pide cuentas sobre el uso que se hace de ellos suelen surgir dificultades de carácter político. Estas dificultades se presentan porque hay un apoyo disperso a las reformas de este tipo por parte de quienes se benefician de ellas, pero también hay oponentes organizados a las reformas, debido a que ellas cambian los incentivos o las reglas del juego (Grindle, 2004). Por eso hay que tener claro que mejorar las prestaciones y establecer una vinculación adecuada entre lo sectorial y lo selectivo tiene una fuerte connotación política, en la medida en que se intenta modificar las instituciones para mejorar la calidad y equidad de los servicios. Ello implica ligar el control financiero, por ejemplo, al desempeño del servicio, hacer que las instituciones rindan cuentas y tener una visión integral de aspectos que hasta ahora han funcionado como compartimentos estancos. La viabilidad política puede topar con serios obstáculos por la resistencia de quienes hasta ahora están brindando los servicios de una determinada manera.

En cuanto a lo sectorial, en México ha resultado polémica una transferencia creada recientemente por el programa Oportunidades, que es una suerte de pensión asistencial, ${ }^{17}$ e incluso el vínculo con el aseguramiento en salud provisto por el Seguro Popular

\footnotetext{
16 Los actuales desafíos que encara la educación costarricense se analizan en Garnier (2007).

${ }^{17}$ El Mecanismo de Ahorro para el Retiro Oportunidades (MAROP).
} 
de Salud (BID, 2006). ${ }^{18}$ Se ha planteado que antes es conveniente consolidar los vínculos con las prestaciones de salud primaria y de educación ya establecidas (Gertler, 2006).

En este caso, el aspecto más importante tiene que ver más bien con la arquitectura de la protección social - que hasta ahora es dual en cuanto a la protección contributiva y no contributiva de los sectores formal e informal-, tanto por sus repercusiones como por el sentido que tiene esta transferencia monetaria dentro del financiamiento no contributivo de la protección social en pensiones (BID, 2006; Levy, 2006). ${ }^{19}$ Tal preocupación es la antípoda de las políticas aplicadas en Chile bajo la dictadura militar, cuando la focalización fue ancilar a la instauración de sistemas duales de salud y de previsión. En el caso mexicano, por el contrario, se discute actualmente si la lucha contra la pobreza puede afectar el alcance y la naturaleza de la seguridad social y la posibilidad de contribuir a la superación de la dualidad también desde la lucha contra la pobreza. ${ }^{20}$

Ahora bien, si situamos los elementos de esta polémica en una perspectiva más general sobre las transferencias condicionadas, puede advertirse que la coordinación con lo sectorial es más compleja cuando implica prestaciones - por ejemplo, en salud y educación, debido a motivos de cobertura y oferta ya analizados - con las cuales se pretende lograr efectos en el capital humano. Otro es el caso de las pensiones, que son estrictamente transferencias monetarias: en este caso, la complejidad de gestión tiene que ver con la recaudación, los procesos de entrega y las eventuales contraprestaciones a las que se condicionen y su respectiva certificación. En términos de política social, a la arquitectura previsional en que se insertan.

\footnotetext{
18 Por ejemplo, se ha postulado que el programa Oportunidades no debe otorgar beneficios condicionados al estatus laboral de las familias beneficiarias. En ese sentido, para promover el empleo formal "se trata de alinear los incentivos" y en cuanto a pensiones se ha propuesto eliminar el MAROP, para analizar un sistema coherente de seguridad social, por ejemplo, con un pilar solidario no contributivo (BID, 2006, p. 16), lo que es coherente con los planteamientos de Levy (2006). En este contexto se está redefiniendo el MAROP, para hacerlo "portable" y complementario (Gómez-Hermosillo, 2006).

${ }^{19}$ Sobre las dificultades políticas recientes de México para reformar la protección social en salud, vinculada con la de pensiones, véase González (2005) y una versión resumida de ese trabajo en Sojo y Uthoff (2007).

20 Véase en Durán (2007) un valioso análisis sobre formas de financiamiento de las pensiones no contributivas en Costa Rica,
}

Las transferencias condicionadas forman parte de los procesos de descentralización que están en marcha en la región. Las municipalidades participan en la selección de beneficiarios, en la verificación de que se cumpla con las contraprestaciones y en la gestión de las transferencias monetarias, lo cual puede llevar a apreciables variaciones en esos planos (de Janvry, Finan y otros, 2005, p. 3), a diferentes asociaciones entre el poder central y el descentralizado, y a efectos en las economías locales. En diciembre del 2003, las transferencias del programa Bolsa Familia representaban para la región norte de Brasil un $15 \%$ de los recursos del Fondo de participación municipal, un $28 \%$ para la región noreste, un $10 \%$ para la sudeste, un $8 \%$ para la sur y un $7 \%$ para la centro-oeste, mostrando así el impacto redistributivo interregional (Cohn y Medeiros, 2004).

Además, se advierte un discurso más flexible en cuanto a la combinación público-privada en la prestación de los servicios focalizados, ya que aumenta el reconocimiento de que ningún aspecto de las prestaciones y de su impacto - léase calidad, eficacia, eficiencia o equidad—, está garantizado simplemente por el carácter público o privado de la prestación. Esto es así tanto respecto de ampliar la prestación por parte de privados, como es el caso del Seguro Popular de Salud en México (Sojo, 2006), como respecto de no demonizar más la prestación estatal, reconociendo las fallas y asimetrías del mercado que llevan a excluir sectores de alto riesgo y bajos ingresos.

Cabe además analizar y controlar el surgimiento de incentivos perversos. Por ejemplo, para padres y maestros: paradójicamente, los bonos pueden fomentar la repetición de años lectivos en ciertas zonas rurales, donde las barreras a la continuidad educativa interactúan con las condiciones de acceso a esos bonos. He aquí nuevamente un aspecto que pone de relieve la necesidad de sinergia entre las reformas sectoriales y los programas focalizados, en este caso con la eliminación de las barreras a la continuidad educativa, lo cual remite también a la oferta sectorial.

considerando el crecimiento económico, la viabilidad fiscal y los escenarios actuariales. Asimismo, véase en Uthoff (2007) el examen de la reforma en marcha del sistema previsional chileno, que trasciende una visión asistencial y modifica la arquitectura del sector, imprimiéndole solidaridad. 


\section{VI}

\section{La selectividad más allá}

\section{de la lucha contra la pobreza}

Las garantías de prestaciones en salud son políticas selectivas, aunque distintas a las políticas contra la pobreza, por sus propósitos más amplios y por la cobertura vertical que pueden implicar, es decir, por el tipo de prestaciones que ofrecen. Sin embargo, en algunas experiencias, como las de Guatemala o Bolivia, tales garantías pueden verse subsumidas en las políticas contra la pobreza porque sus beneficiarios son pobres. ${ }^{21}$ No sucede así en el caso del Seguro Popular en Salud de México que, pese a dirigirse primordialmente a los pobres excluidos de los sistemas de aseguramiento, permite la afiliación de otros estratos de ingreso y cubre algunas prestaciones de alto costo. Tampoco en el caso de las garantías explícitas en salud (GES) de Chile, por el tipo de prestaciones y por los sectores de ingreso que con ellas se benefician y que constituyen un paso hacia una mayor universalidad efectiva en salud.

Es necesario recordar que los objetivos e instrumentos de la política social remiten a un acuerdo acerca del bienestar socialmente deseable y de los medios óptimos para alcanzarlo, que puede cristalizar en la formulación de derechos sociales. En ese sentido, desde el punto de vista jurídico, las garantías son dispositivos idóneos para asegurar la eficacia de las normas que reconocen los derechos. En el caso de los derechos de propiedad y de libertad, su goce está claramente establecido por garantías. Los derechos sociales, por el contrario, generalmente carecen de un sistema de garantías equiparable en su capacidad de regulación y control, y adecuado a su naturaleza. De allí que el desarrollo de los derechos sociales, incluso en los Estados de bienestar europeos, haya tenido lugar en gran medida gracias a la ampliación de la discrecionalidad de los aparatos burocráticos. Aun cuando estén identificados los derechos sociales y sus contenidos - situación que, con mucho, no constituye la norma en la región-, para determinar los potenciales alcances de su protección es preciso establecer herramientas que aseguren que podrán hacerse efectivos. Por lo tanto, las garantías de los derechos son precisamente los métodos, mecanismos o dispositivos que sirven para asegurar que un derecho efectivamente pueda ejercerse.

\footnotetext{
${ }^{21}$ Esta sección se basa en Sojo (2006).
}

En definitiva, las garantías son instrumentos para que los derechos no sean letra muerta, sino exigibles, operables y ejecutables (Ferrajoli, 2002; Courtis, 2007).

La carencia de esas garantías es un factor de ineficacia de los derechos sociales. En este sentido, la ausencia de garantías sociales o positivas adecuadas puede conducir a prácticas burocráticas propias del Estado asistencial y del orientado a beneficiar a clientelas políticas, que son terreno fértil para la corrupción y las decisiones arbitrarias. Por ello, algunas reformas recientes de la política social, tales como las cartas de derechos de los usuarios, complementan las garantías jurídicas que sustentan estos derechos. Las garantías de prestaciones de salud pueden analizarse justamente en esa perspectiva. Cada una ha estado determinada por el derrotero propio del sistema de salud en que se inserta y por las restricciones políticas encaradas, y todas encaran retos pendientes.

En países con sistemas de salud poco desarrollados, con muy bajos niveles de aseguramiento para la población de bajos ingresos, y que sufren procesos de transición epidemiológica polarizada, la garantía de prestaciones se ha abocado sobre todo a la atención primaria en salud y a la atención materno-infantil. Estas prestaciones, si bien son de bajo costo relativo, representan un esfuerzo respecto del punto de partida. En países con tales características la garantía de prestaciones tiene un efecto muy acotado en cuanto a la reorganización global del sistema de salud. En el caso de Guatemala, se prescindió de la separación de funciones planteada al inicio. En Guatemala y Bolivia las garantías se dan en el marco de un paquete de prestaciones, pero sin especificar garantías de oportunidad y de acceso, y sin repercusiones en la arquitectura del aseguramiento.

La garantía de prestaciones de salud en Chile es la más avanzada de la región, ya que las prestaciones garantizadas que se introdujeron en el 2005 comprenden algunas de alto costo e incluyen garantías de oportunidad, acceso, protección financiera y calidad. Además, tiene repercusiones en la combinación público-privada de atención en salud, porque impugna parcialmente la dualidad básica del sistema de aseguramiento, acotando las prácticas de selección adversa de las instituciones de salud previsional (ISAPRES) e incrementando la 
transparencia de las coberturas. La trayectoria de la reforma evidencia las dificultades políticas que impidieron implantar medidas que hubieran otorgado mayor solidaridad al sistema dual de aseguramiento, como podría haber sido la introducción de un fondo de solidaridad. El cumplimiento efectivo de las garantías involucra grandes desafíos: hasta julio del 2006 fueron atendidos dos millones de personas. Los reclamos de incumplimiento presentados se refirieron en 367 casos a la garantía de acceso, y en 475 a la de oportunidad. Se ha hecho evidente la necesidad de mejorar la gestión de los procesos para contar, entre otros aspectos, con un sistema de alertas y de detección de carencias, y para adecuar redes de prestación. ${ }^{22}$

En México, con el fin de avanzar hacia la cobertura universal, la garantía de prestaciones se introdujo mediante una reforma al sistema de aseguramiento que, sin embargo, no modificó su segmentación. Con el fin de acotar los gastos de los hogares ante situaciones de salud catastróficas, se

\section{VII}

\section{Conclusiones}

En resumidas cuentas, se ha comprobado que en materia de focalización no hay orientaciones que resulten ajenas a la dinámica de los sectores sociales, ya que implican sinergias o relaciones competitivas. Haber distinguido aquí cuatro hitos en la trayectoria de las políticas selectivas ha permitido mostrar que a lo largo de las cuatro últimas décadas, las políticas de focalización encaminadas a superar las causas de la pobreza, o que solo atacan sus manifestaciones, han repercutido en la dinámica de los sectores sociales. La focalización reduccionista ha cumplido una función subordinada respecto de reformas sectoriales cuyo objetivo ha sido desmantelar o debilitar las políticas de carácter universal. En el polo opuesto, cuando se quiere superar un enfoque asistencial en la

${ }^{22}$ Por ejemplo, los casos de prematurez que se ha debido atender han sido más que los proyectados (Urriola, 2006). agregó un seguro con nuevos recursos que tiene algunos vínculos con el resto de los prestadores, pero no en el ámbito financiero. Llama la atención la complejidad del financiamiento, debido tanto a la diversidad de los fondos de que se nutre el Seguro Popular de Salud como a los diversos mecanismos financieros asociados con ellos. La reforma ha implicado modificaciones de la combinación público-privada, ya que ha ampliado la participación de prestadores privados. A diferencia de Chile, la cobertura no está reforzada por garantías adicionales.

En todos estos casos, la selectividad está dada por el espectro de prestaciones que se considera. En términos institucionales, la lógica es eminentemente sectorial y, según sus singularidades, acarrea una organización de entidades prestadoras bajo esa lógica: equipos básicos de atención en salud que operan a través de diversas combinaciones público-privadas de prestadores y en diferentes regímenes de descentralización a escala nacional y sectorial.

lucha contra la pobreza, se necesitan reformas sectoriales destinadas a ampliar la cobertura y mejorar la calidad de las prestaciones.

Este trabajo abordó también dos tendencias en materia de focalización en campos que trascienden lo que es estrictamente la lucha contra la pobreza. Por una parte, la propuesta también reduccionista del manejo del riesgo social, elaborada para el ámbito del aseguramiento, que socava el principio de solidaridad, subestima los problemas de equidad derivados del aseguramiento de mercado y recorta drásticamente el ámbito sectorial. Y por otra, en sentido contrario, la garantía de prestaciones en salud, que representa políticas de carácter selectivo, con propósitos más amplios y que, en algunos casos, involucra prestaciones de alto costo, un sector de salud más vigoroso y una regulación de la combinación público-privada favorable al principio de solidaridad. Ambas tendencias tienen repercusiones en lo sectorial. 
APÉNDICE

\section{América Latina: programas de transferencia de ingreso y prestaciones sociales condicionadas}

\begin{tabular}{|c|c|c|c|c|}
\hline Programa y país & $\begin{array}{l}\text { Año de } \\
\text { inicio }\end{array}$ & Objetivo & Beneficios & $\begin{array}{l}\text { Requisitos para } \\
\text { recibir beneficios }\end{array}$ \\
\hline $\begin{array}{l}\text { Bolsa Familia y Hambre } \\
\text { cero, Brasil }\end{array}$ & 2003 & $\begin{array}{l}\text { Combatir el hambre, la pobreza y otras formas } \\
\text { de privación familiar; promover la seguridad } \\
\text { alimentaria y nutricional y el acceso a redes } \\
\text { de servicios públicos de salud, educación y } \\
\text { asistencia social, creando posibilidades de } \\
\text { emancipación sostenible de las familias y }\end{array}$ & Transferencia de ingreso & $\begin{array}{l}\text { Seguimiento de la salud y el estado } \\
\text { nutricional de los niños; matrícula y } \\
\text { asistencia a clases de todos los niños en } \\
\text { edad escolar; participación en acciones } \\
\text { de educación alimentaria }\end{array}$ \\
\hline
\end{tabular}

$\begin{array}{lll}\text { Bolsa Escola, Brasil } 2001 & \begin{array}{l}\text { Aumentar el logro educativo de niños Beca escolar a niños pobres entre } \\ \text { pobres en edad escolar. Reducir la pobreza } 6 \text { y } 15 \text { años que asisten a la escuela } \\ \text { actual y futura }\end{array}\end{array}$

Programa de Erradicación del Trabajo Infantil (PETI), Brasil
1998 Erradicar el trabajo infantil, aumentando el Transferencia de ingreso; logro educativo y reduciendo la pobreza
Programa post-escuela
$\mathrm{Al}$ menos $85 \%$ de asistencia escolar en períodos de 3 meses

$\mathrm{Al}$ menos $80 \%$ de asistencia escolar en período de 3 meses y participación en el programa post-escuela (jornada ampliada)

Cumplir calendario de visitas a centro de salud y cumplir con el programa de vacunaciones

\section{Bolsa alimentação, $\quad 2000$ Reducir deficiencias nutricionales y la Beca de salud} Brasil mortalidad infantil

2003 Contribuir al fortalecimiento del capital Transferencia de ingreso mensual

Bono de Desarrollo Humano, Ecuador humano, físico y social de las personas, familas y comunidades que viven en condiciones de riesgo y pobreza

Matrícula y asistencia de los niños a la escuela; asistencia a controles de salud; participar en charlas ligadas al programa

\begin{tabular}{|c|c|c|}
\hline $\begin{array}{l}\text { Jefes y Jefas de Hogar, } \\
\text { Argentina }\end{array}$ & 2001 & $\begin{array}{l}\text { Entregar apoyo a familias con dependientes } \\
\text { que habían perdido su fuente de ingresos }\end{array}$ \\
\hline $\begin{array}{l}\text { Familias en Acción, } \\
\text { Colombia }\end{array}$ & 2001 & $\begin{array}{l}\text { Aumentar la inversión en capital humano en } \\
\text { familias de extrema pobreza. Servir como } \\
\text { "red de seguridad" }\end{array}$ \\
\hline $\begin{array}{l}\text { Programa de } \\
\text { Asignación Familiar } \\
\text { (PRAF II), Honduras }\end{array}$ & 1990 & $\begin{array}{l}\text { Aumentar la acumulación de capital humano } \\
\text { en los niños de las familias más pobres, ayu- } \\
\text { dando a romper el círculo de pobreza }\end{array}$ \\
\hline
\end{tabular}

Transferencia de 150 pesos argentinos Contraprestaciones laborales por mes

Subsidio nutricional a familias con Visitas regulares a centros de salud para niños menores de 7 años; subsidio monitoreo de crecimiento de niños; al escolar para familias con niños de 7 a menos $80 \%$ de asistencia a la escuela 17 años en la escuela en períodos de 2 meses

Bono escolar, bono nutricional y de Inscripción en la escuela y máximo de salud; entrenamiento en nutrición 7 días de ausentismo en un período de para madres; incentivos a la oferta 3 meses; cumplir con visitas regulares a para escuelas primarias y para centros centros de salud de salud

Programa Oportunidades, México

Chile Solidario, Chile 2002

Plan Nacional de Empleo de Emergencia (LANE), Bolivia

Red de Protección Social, Nicaragua

2000 Promover la acumulación de capital humano de hogares en extrema pobreza mejorando el nivel educativo y de salud y el estado nutricional de los niños y las
2001 Reducir el impacto de la pérdida de empleo Transferencia de ingreso en la población más pobre, mediante empleo temporal masivo en áreas urbanas y rurales, financiando salarios a personas desocupadas que realizan actividades de mantenimiento y pequeñas obras tendientes al bien común proveyendo recursos que permitan recupera o disponer de una capacidad funcional y resolutiva eficaz en el entorno personal, familiar, comunitario e institucional en el tiempo Transferencia de ingreso, apoyos educativos, paquete alimenticio

$$
\begin{aligned}
& \text { programa; acudir a citas } \\
& \text { en los servicios de salud }
\end{aligned}
$$

Asistencia de más del $85 \%$ a clases; participar en charlas educativas del

Transferencia de ingreso que decrece Asistencia escolar y controles de salud otras responsabilidades familiares

\section{Prestaciones laborales}

Bono alimentario destinado a alimentación.

Bono educativo para hogares con niños entre 6 y 13 años. Cada dos meses se entrega a la titular 0,7 dólares por niño(a) matriculado(a), para que a su vez lo entregue a la escuela
Matrícula y asistencia a la escuela; participación en charlas educativas del programa

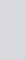




\section{Bibliografía}

Alvarez, C. (2006): Oportunidades: presente y futuro. Temporalidad y graduación, exposición en el Seminario "Oportunidades: presente y futuro", organizado por el Instituto Nacional de Salud Pública (INSP), la Universidad Iberoamericana, el Centro de Investigación y Docencia Económica (CIDE) y el Centro de Investigaciones y Estudios Superiores en Antropología Social (CIESAS), Juitepec, México, octubre.

Atkinson, A.B. (1995): On targeting social security: theory and Western experience with family benefits, en D. Van de Walle y K. Nead (comps.), Public Spending and the Poor. Theory and Evidence, Baltimore, The Johns Hopkins University Press.

Banco Mundial (1997): Informe sobre el desarrollo mundial: el estado en un mundo en transformación, 1997, Washington, D.C.

(2001): Social Protection Sector Strategy: from Safety Net to Spring Board, Washington, D.C., enero.

(2002): Social Funds. A Review of World Bank Experience, Informe $\mathrm{N}^{\mathrm{o}}$ 23668, Washington, D.C., mayo.

Berar Awad, A. (1997): Social Funds Revisited. An Overview with a Particular Focus on Employment and Gender Dimensions, Ginebra, Organización Internacional del Trabajo (OIT).

BID (Banco Interamericano de Desarrollo) (2006): Protección social, seguridad social y oportunidades: ¿un conjunto de incentivos alineados?, Nota de política, Washington, D.C., Departamento de integración y programas regionales, División de programas sociales, septiembre.

Barahona, M. (2006): El marco general de la política para el combate de la pobreza, en F. Herrero y G, González (comps.), Pobreza: talón de Aquiles del desarrollo costarricense, San José, PROCESOS.

CEPAL (Comisión Económica para América Latina y el Caribe) (1994): Experiencias recientes de selección de beneficiarios en Costa Rica: una evaluación del Sistema de Beneficiarios de los Proyectos Sociales (SISBEN), LC/R.1476, Santiago de Chile.

(1998): Políticas contra la pobreza en Honduras, LC/R.1794, Santiago de Chile, junio.

(2000): Equidad, desarrollo y ciudadanía, LC/G.2071/Rev. 1$\mathrm{P}$, Santiago de Chile. Publicación de las Naciones Unidas, $\mathrm{N}^{\mathrm{o}} \mathrm{de}$ venta: S.00II.G.81.

(2006), La protección social de cara al futuro: acceso, financiamiento y solidaridad, LC/G.2294(SES.31/3), Santiago de Chile.

Chenery, H. y otros (1976): Redistribución con crecimiento, Madrid, Tecnos.

Cohn, A. y A.M. Medeiros (2004): O programa Bolsa família: a questão social no Brasil, inédito.

Cornia, A. (1999): Social funds in stabilization and adjustment programmes, International Monetary and Financial Issues for the 1990s: Research Papers for the Group of Twenty-Four, UNCTAD/GDS/MDPB, Nueva York, Naciones Unidas. Publicación de las Naciones Unidas, $\mathrm{N}^{\circ}$ de venta: E.99.II.D.25.

Courtis, Ch. (2007): Los derechos sociales en perspectiva: la cara jurídica de la política social en América Latina, en A. Sojo y A. Uthoff (comps.), Desempeño económico y política social en América Latina y el Caribe: los retos de la equidad, el desarrollo y la ciudadanía, México, D.F., Editorial Fontamara.

De Janvry, A. y E. Sadoulet (2005): Making Conditional Cash Transfer Programs More Efficient: Designing for Maximum Effect of the Conditionality, Berkeley, Universidad de California en Berkeley. Disponible en are.berkeley.edu/ sadoulet/papers/ TargetingMay05.pdf.

De Janvry, A., F. Finan y otros (2005): Evaluating Brazil's Bolsa Escola Program: Governance and Decentralized Implementation, julio. Disponible en are.berkeley.edu/ finan/BolsaEscolaReport1.pdf.

Draibe, S. (2006): Brasil: Bolsa Escola y Bolsa Família, en E. Cohen y R. Franco (coords.), Transferencias con corresponsabilidad.
Una mirada latinoamericana, México, D.F., Secretaría de Desarrollo Social (SEDESOL).

Durán, F. (2007): Estrategias para la universalización de la cobertura del sistema de pensiones, en A. Sojo y A. Uthoff (comps.), Desempeño económico y política social en América Latina y el Caribe: los retos de la equidad, el desarrollo y la ciudadanía, México, D.F., Editorial Fontamara.

Ferrajoli, L. (2002): Derechos y garantías: la ley del más débil, Madrid, Editorial Trotta.

Franco, R. (1990): La focalización como criterio para aumentar la eficiencia de la política social, LC/IP/L.33, Santiago de Chile, Instituto Latinoamericano y del Caribe de Planificación Económica y Social (ILPES).

(1996): Los paradigmas de la política social en América Latina, Revista de la CEPAL, No 58, LC/G.1916-P, Santiago de Chile, abril.

Galasso, E. y M. Ravallion (2003): Social Protection in a Crisis: Argentina's Plan Jefes y Jefas, World Bank Policy Research Working Paper, $\mathrm{N}^{\circ} 3165$, Washington, D.C., noviembre. Disponible en http://www.undp-povertycentre.org/publications/ social/SocialProtection_in_a_Crisis-Argentina_Galasso-Ravallion-WB-.pdf.

Garnier, L. (2007): Una educación para saber producir, saber vivir, y saber convivir, en A. Sojo y A. Uthoff (comps.), Cohesión social en América Latina y el Caribe: una revisión perentoria de algunas de sus dimensiones, Santiago de Chile, Comisión Económica para América Latina y el Caribe (CEPAL), en prensa.

Gertler, P. (2006): Oportunidades 2006: Where do we go from here?, exposición en el Seminario "Oportunidades: presente y futuro", organizado por el Instituto Nacional de Salud Pública (INSP), la Universidad Iberoamericana, el Centro de Investigación y Docencia Económica (CIDE) y el Centro de Investigaciones y Estudios Superiores en Antropología Social (CIESAS), Juitepec, México, octubre.

Gobierno de Costa Rica (1996): Plan nacional de lucha contra la pobreza. Hacia una Costa Rica integrada por las oportunidades, San José, Editorial Hombres de maíz, abril.

Gómez-Hermosillo, R. (2006): Oportunidades: lecciones y retos, exposición en el Seminario "Oportunidades: presente y futuro", organizado por el Instituto Nacional de Salud Pública (INSP), la Universidad Iberoamericana, el Centro de Investigación y Docencia Económica (CIDE) y el Centro de Investigaciones y Estudios Superiores en Antropología Social (CIESAS), Juitepec, México, octubre.

González, A. (2005): La factibilidad política de las reformas del sector social en América Latina, serie Estudios y perspectivas, $\mathrm{N}^{\circ} 39$, LC/L.2412-P, México, D.F., Sede Subregional de la CEPAL en México, noviembre. Publicación de las Naciones Unidas, $\mathrm{N}^{\circ} \mathrm{de}$ venta: S.05.II.G.159.

Grindle, M. (2004): Despite the Odds: The Contentious Politics of Education, Princeton, Princeton University Press.

Hernández, M. (2006): Coordinación sectorial y mejora de la calidad de los servicios de salud y educación, exposición en el Seminario "Oportunidades: presente y futuro", organizado por el Instituto Nacional de Salud Pública (INSP), la Universidad Iberoamericana, el Centro de Investigación y Docencia Económica (CIDE) y el Centro de Investigaciones y Estudios Superiores en Antropología Social (CIESAS), Juitepec, México, octubre.

Holzmann, R. y S. Jorgensen (2000): Social Risk Management: a New Conceptual Framework for Social Protection and Beyond, Social Protection Discussion Paper, $N^{\circ}$ 6, Washington, D.C., Banco Mundial, febrero.

Levy, S. (2006): Creación de empleos y reducción de la pobreza, exposición en el Seminario "Oportunidades: presente y futuro", organizado por el Instituto Nacional de Salud Pública (INSP), 
la Universidad Iberoamericana, el Centro de Investigación y Docencia Económica (CIDE) y el Centro de Investigaciones y Estudios Superiores en Antropología Social (CIESAS), Juitepec, México, octubre.

López Calva, L.F. (2006): Oportunidades y política social en México, exposición en el Seminario "Oportunidades: presente y futuro", organizado por el Instituto Nacional de Salud Pública (INSP), la Universidad Iberoamericana, el Centro de Investigación y Docencia Económica (CIDE) y el Centro de Investigaciones y Estudios Superiores en Antropología Social (CIESAS), Juitepec, México, octubre.

Mancera, C. (2006): Coordinación sectorial Oportunidades-educación, exposición en el Seminario "Oportunidades: presente y futuro", organizado por el Instituto Nacional de Salud Pública (INSP), la Universidad Iberoamericana, el Centro de Investigación y Docencia Económica (CIDE) y el Centro de Investigaciones y Estudios Superiores en Antropología Social (CIESAS), Juitepec, México, octubre.

Meneses, F., B. Almodóvar y otros (2005): Evaluación del cumplimiento de las metas, los costos unitarios y el apego del Programa a las reglas de operación 2004, en B. Hernández Prado y M. Hernández (comps.), Evaluación externa de impacto del Programa Oportunidades 2004, Tomo IV. Aspectos económicos y sociales, México, D.F., Instituto Nacional de Salud Pública.

Mesa-Lago, C. (1993): Safety Nets and Social Funds to Alleviate Povery: Performance, Problems and Poverty Options, Ginebra, octubre.

Midgley, M. (1995): Reductive megalomania, en J. Cornwell (org.), Nature's Imagination: the Frontiers of Scientific Vision, Nueva York, Oxford University Press.

Orozco, M. y C. Hubert (2005): La focalización en el programa de desarrollo humano Oportunidades de México, Serie de documentos de discusión sobre la protección social, $\mathrm{N}^{\mathrm{o}}$ 531, Washington, D.C., Banco Mundial, junio.

Palma, J. y R. Urzúa (2005): Anti-poverty Policies and Citizenry: the 'Chile Solidario' Experience, Management of Social Transformation series (MOST2), Policy Papers $\mathrm{N}^{\mathrm{o}} 12$, París, Organización de las Naciones Unidas para la Ciencia y la Cultura (UNESCO). Disponible en http://unesdoc.unesco.org/ images/0014/001402/140240e.pdf

Parker, S. (2006): Coordinación sectorial o mejora de la calidad de los servicios de educación, exposición en el Seminario "Oportunidades: presente y futuro", organizado por el Instituto Nacional de Salud Pública (INSP), la Universidad Iberoamericana, el Centro de Investigación y Docencia Económica (CIDE) y el Centro de Investigaciones y Estudios Superiores en Antropología Social (CIESAS), Juitepec, México, octubre.

Pritchett, L. (2005): The Political Economy of Targeted Safety Nets, Serie de documentos de discusión sobre la protección social, $\mathrm{N}^{\circ}$ 501, Washington, D.C., Banco Mundial, enero.

Raczynski, D. (1991): La ficha CAS y la focalización de los programas sociales, Notas Técnicas CIEPLAN, $\mathrm{N}^{\circ} 141$, Santiago de Chile, agosto.

Rawlings, L.B. (2004): A New Approach to Social Assistance: Latin America's Experience with Conditional Cash Transfer Programs, Serie de documentos de discusión sobre la protección social, $\mathrm{N}^{\circ}$ 0416, Washington, D.C., Banco Mundial, agosto. Disponible en http://wbln0018.worldbank.org/HDNet/HDdocs.nsf/0/ 4BB6997285F65EF585256EE5005E3A75?OpenDocument.

Sánchez, M. (2005): Reformas económicas, régimen cambiario y choques externos: efectos en el desarrollo económico, la desigualdad y la pobreza en Costa Rica, El Salvador y Honduras, serie Estudios y perspectivas, N ${ }^{\circ}$ 36, LC/L.2370-P, México, D.F., Sede Subregional de la CEPAL en México, agosto. Publicación de las Naciones Unidas, $\mathrm{N}^{\mathrm{o}}$ de venta: S.05.II.G.11.

SEDESOL (Secretaría de Desarrollo Social) (2004): Ley General de Desarrollo Social, Diario oficial, México, D.F., 20 de enero.
Sen, A. (1995): The political economy of targeting, en D. Van de Walle y K. Nead (comps.), Public Spending and the Poor. Theory and Evidence, Baltimore, The Johns Hopkins University Press.

Serrano, C. (2005): La política social en la globalización. Programas de protección en América Latina, serie Mujer y desarrollo, No 70, LC/L.2364-P, Santiago de Chile, agosto. Publicación de las Naciones Unidas, $\mathrm{N}^{\mathrm{o}}$ de venta: S.05.II.G.103.

Serrano, C. y D. Raczynski (2003): Derechos sociales básicos, superación de la pobreza y protección social ante la vulnerabilidad. Asesorías para el desarrollo, mayo, inédito.

Sojo, A. (1990): Naturaleza y selectividad de la política social, Revista de la CEPAL, $\mathrm{N}^{\circ}$ 41, LC/G.1631-P, Santiago de Chile, agosto.

(1993): La política social en Costa Rica: panorama de sus reformas recientes, serie Reformas de políticas públicas, $\mathrm{N}^{\circ}$ 17, LC/L.784, Santiago de Chile, Comisión Económica para América Latina y el Caribe (CEPAL), noviembre. Publicado también en Cuadernos de ciencias sociales, $\mathrm{N}^{\circ} 67$, San José, Facultad Latinoamericana de Ciencias Sociales (FLACSO), febrero de 1994

(1996): Posibilidades y límites de la reforma en la gestión de la salud en Chile, Revista de la CEPAL, N 59, LC/G.1931-P, agosto, Santiago de Chile.

(1999): La política social en la encrucijada: opciones o disyuntivas, en J. Carpio e I. Novacovsky (comps.), De igual a igual: el desafío del Estado ante los nuevos problemas sociales, Buenos Aires, Fondo de Cultura Económica (FCE).

(2000): Moving social protection beyond a 'safety net' approach in Latin America and the Caribbean, Deutsche Stiftung fuer Entwicklung (DSE) Issue Notes. The Challenge of Social Protection in a Globalizing World, Berlin. Disponible en http://www.dse.de/ef/social/sojo.htm.

(2003): Vulnerabilidad social, aseguramiento y diversificación de riesgos en América Latina y el Caribe, Revista de la CEPAL, $\mathrm{N}^{\circ}$ 80, LC/G.2204-P, Santiago de Chile, agosto.

(2006): La garantía de prestaciones en salud en América Latina: equidad y reorganización de los cuasimercados a inicios del milenio, serie Estudios y perspectivas, $\mathrm{N}^{\circ} 44$, LC/L.2484-P, México, D.F., Sede Subregional de la CEPAL en México, febrero. Publicación de las Naciones Unidas, $\mathrm{N}^{\mathrm{o}} \mathrm{de}$ venta: S.06.II.G.9

(2007): Políticas selectivas y sectoriales en América Latina: su vínculo institucional en la lucha contra la pobreza, en A. Sojo y A. Uthoff (comps.), Desempeño económico y política social en América Latina y el Caribe: los retos de la equidad, el desarrollo y la ciudadanía, México, D.F., Editorial Fontamara.

Sojo, A. y A. Uthoff (comps.) (2007): Desempeño económico y política social en América Latina y el Caribe: los retos de la equidad, el desarrollo y la ciudadanía, México, D.F., Editorial Fontamara.

Urriola, R. (2006): Algunos comentarios para evaluar el primer año del plan AUGE en el sistema público de salud, inédito.

Uthoff, A. (2007): La capitalización de cuentas individuales: solidaridad y sustentabilidad como objeto de la reforma previsional en Chile, en A. Sojo y A. Uthoff (comps.), Cohesión social en América Latina y el Caribe: una revisión perentoria de algunas de sus dimensiones, Santiago de Chile, en prensa.

Van de Walle, D. (1995): Incidence and targeting: an overview of implications, en D. Van de Walle y K. Nead (comps.), Public Spending and the Poor. Theory and Evidence, Baltimore, The Johns Hopkins University Press, diciembre.

Vergara, P. (1990): Políticas hacia la extrema pobreza en Chile 1973 1988, Santiago de Chile, Facultad Latinoamericana de Ciencias Sociales (FLACSO).

Zumbado, F. (2006): La política de superación de la pobreza de la administración Arias Sánchez (2006-2010), en F. Herrero y G. González (comps.), Pobreza: talón de Aquiles del desarrollo costarricense, San José, PROCESOS. 